\title{
Offense versus defense: responses of three morphological types of lobsters to predation
}

\author{
Diana E. Barshaw ${ }^{1,4, *}$, Kari L. Lavalli ${ }^{1,3}$, Ehud Spanier ${ }^{1,2}$ \\ ${ }^{1}$ Leon Recanati Institute for Maritime Studies, and ${ }^{2}$ Department for Maritime Civilizations, University of Haifa, \\ Mount Carmel, Haifa 31905, Israel \\ ${ }^{3}$ The Lobster Conservancy, PO Box 235, Friendship, Maine 04547, USA
}

${ }^{4}$ Present address: Israel Oceanographic \& Limnological Research Institute, PO Box 8030, Haifa 31080, Israel

\begin{abstract}
We compared the antipredator mechanisms of 3 morphological 'types' of lobsters: slipper lobsters Scyllarides latus, spiny lobsters Palinurus elephas and clawed lobsters Homarus gammarus. These lobsters differ in the extent and effectiveness of their weaponry and armor, which we assessed by: (1) field tethering experiments that compared relative survival of intact and manipulated (clinging ability, antennae, or claws removed) lobsters in the face of predation, and (2) measurements of the breaking strength and thickness of the carapace of each species. Intact clawed lobsters suffered higher mortality than either intact slipper or spiny lobsters after both 4 and $24 \mathrm{~h}$. At $24 \mathrm{~h}$, intact spiny lobsters also had higher mortality than intact and manipulated slipper lobsters. The intact spiny and clawed lobsters suffered less predation after $4 \mathrm{~h}$ than the manipulated lobsters (lacking weapons); however, this advantage diminished or vanished by $24 \mathrm{~h}$. This indicates that weapons provided some measure of protection in the short-term, which might be sufficient to allow the lobsters to escape from a predator using a strong abdominal tail flip. Triggerfish Balistes carolinensis were the primary predators on the lobsters. We also saw octopuses Octopus vulgaris feeding on lobsters, but these were never observed subduing a live lobster. 'Punch'-tests (i.e. puncture tests) on the carapaces of each of the 3 species showed that slipper lobsters had stronger armor than either spiny or clawed lobsters, while the spiny lobster armor was intermediate in strength. These results suggest that the defensive strong armor of slipper lobsters is a more effective antipredatory mechanism than the offensive morphological weapons of the spiny and clawed lobsters.
\end{abstract}

KEY WORDS: Predator-prey interactions - Predator-avoidance - Antipredator mechanisms - Weapons · Armor $\cdot$ Lobsters $\cdot$ Scyllarides latus $\cdot$ Palinurus elephas $\cdot$ Homarus gammarus

Resale or republication not permitted without written consent of the publisher

\section{INTRODUCTION}

Related groups of animals can vary greatly in the morphology of certain characters. A possible cause of these variations is the interaction between predators and prey, since predation is an important selective force affecting the fitness of all individuals in prey populations (Edmunds 1974, Harvey \& Greenwood 1978, Sih 1987, Vermeij 1987). Predators affect aspects of their prey beyond that of morphology: they also affect their prey's chemistry, physiology, ecology, and behavior (e.g. Sih 1987), and cause the evolution of a variety of defense traits which Janzen (1981) argues are more diverse than any other array of traits.

Defense traits were traditionally lumped together under the heading of 'antipredator characteristics' (Edmunds 1974, Vermeij 1982), and it was debated whether their evolution required that some prey survived attacks (i.e. 'unsuccessful' or 'incomplete' predation) (Vermeij 1982, 1985, Sih 1985). Subsequently, Sih (1987) and Brodie et al. (1991) divided antipredator characteristics into 2 categories based on whether they functioned before or after a predator detected its prey, i.e. predator-avoidance mechanisms and antipredator mechanisms. Predator-avoidance mechanisms enable 
prey to avoid predation by being active at times when their predators are not active (temporal avoidance), by blending into the background (crypsis), by living where the predators cannot (spatial avoidance), by avoiding notice (immobility), or by sheltering, burying, or reducing general activity levels (slow lifestyle) (Sih 1987, Brodie et al. 1991). These strategies prevent or reduce the likelihood of encounters with predators. In contrast, antipredator mechanisms increase the probability of survival once detected. They include flight, unpredictable movements or changes in form or color (protean behavior), armor, weaponry, distastefulness, venom, and aggregation (Herrnkind et al. 1975, 2001, Endler 1986, Sih 1987, Driver \& Humphries 1988, Lavalli \& Spanier 2001). Sih (1987) argued that the selective pressures resulting in the evolution of these 2 mechanisms differ: predator avoidance mechanisms can evolve in cases of complete predation, i.e. when the prey never survive an attack: those prey that never encounter a predator because of their avoidance mechanisms survive to reproduce and reinforce the avoidance mechanisms. On the other hand, antipredator mechanisms evolve only in the case of unsuccessful predation, whereby prey use an antipredator mechanism to escape and later reproduce (Vermeij 1982, Brodie et al. 1991). Predator-avoidance mechanisms and antipredator mechanisms are, therefore, distinct.

Crustaceans lend themselves to in-depth studies on the evolution of antipredator mechanisms because their morphological weaponry usually comprises modified appendages that can be removed by autotomy with few short-term effects. In the long-term, limb autotomy can impact the ability of crustaceans to feed, grow, and to find mates (Juanes \& Hartwick 1990, Smith 1992), but such long-term effects have little relevance for short-term experiments.

For our investigation on the variations in antipredator mechanisms between related groups, we chose species representative of the 3 major families of lobster: Scyllaridae, Palinuridae, and Nephropidae. These 3 co-occur throughout most of their ranges in the eastern Atlantic Ocean and Mediterranean Sea (Maigret 1978, Fisher et al. 1981, Martins 1985, Williams 1988, Holthuis 1991) (Fig. 1). The slipper lobster Scyllarides latus is found at depths of 4 to $100 \mathrm{~m}$, usually on rocky or sandy bottoms. $S$. latus bears no spines on its flattened carapace, having numerous blunt tubercules instead, and has reduced, shovel-like, flat second antennae. This lobster is capable of retracting its small eyes into sunken orbits (Phillips et al. 1980). The common spiny lobster Palinurus elephas is found at depths of 5 to $160 \mathrm{~m}$, usually on rocky bottoms. Like all other spiny lobsters, it bears sharp spines along the dorsal surface of its carapace and on its long, broad, whip-like second antennae. It has horns protecting its large, stalked eyes (Holthuis 1991, Hunter 1999). The
European clawed lobster, Homarus gammarus, is found at depths of 0 to $150 \mathrm{~m}$ on rocky substrates. Its first walking legs are modified into large claws of unequal size. Its carapace is smooth, with few spines, and it has stalked eyes with no protection.

We compared: (1) the actual effectiveness of the presumed antipredator mechanism of each species,

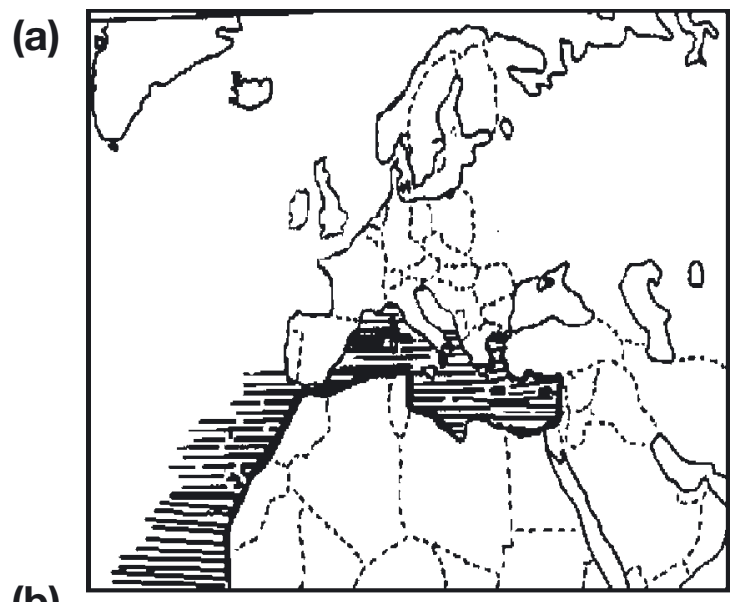

(b)

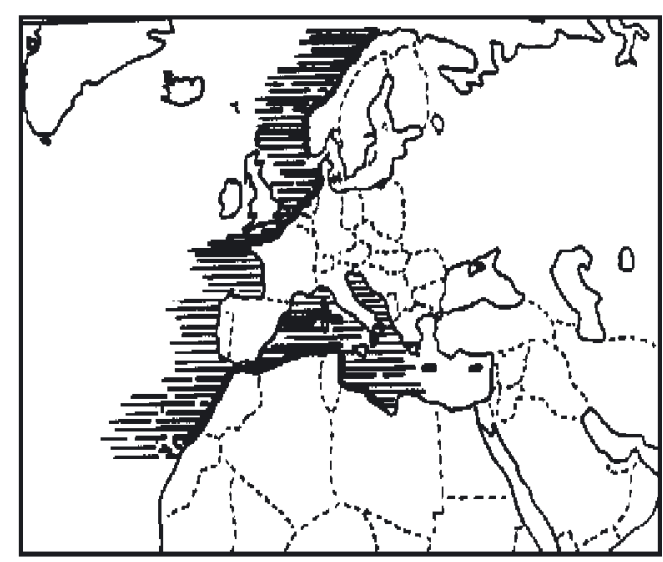

(c)

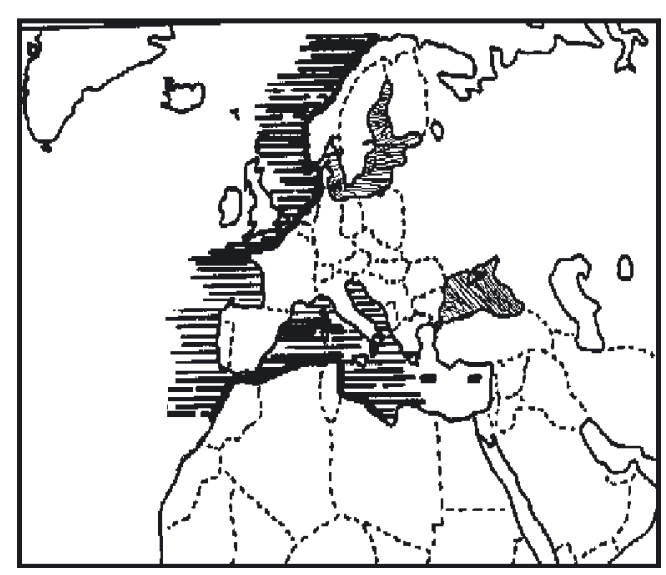

Fig. 1. (a) Scyllarides latus, (b) Palinurus elephas and (c) Homarus gammarus. Geographic range (horizontal lineshading) of the 3 lobster species studied 

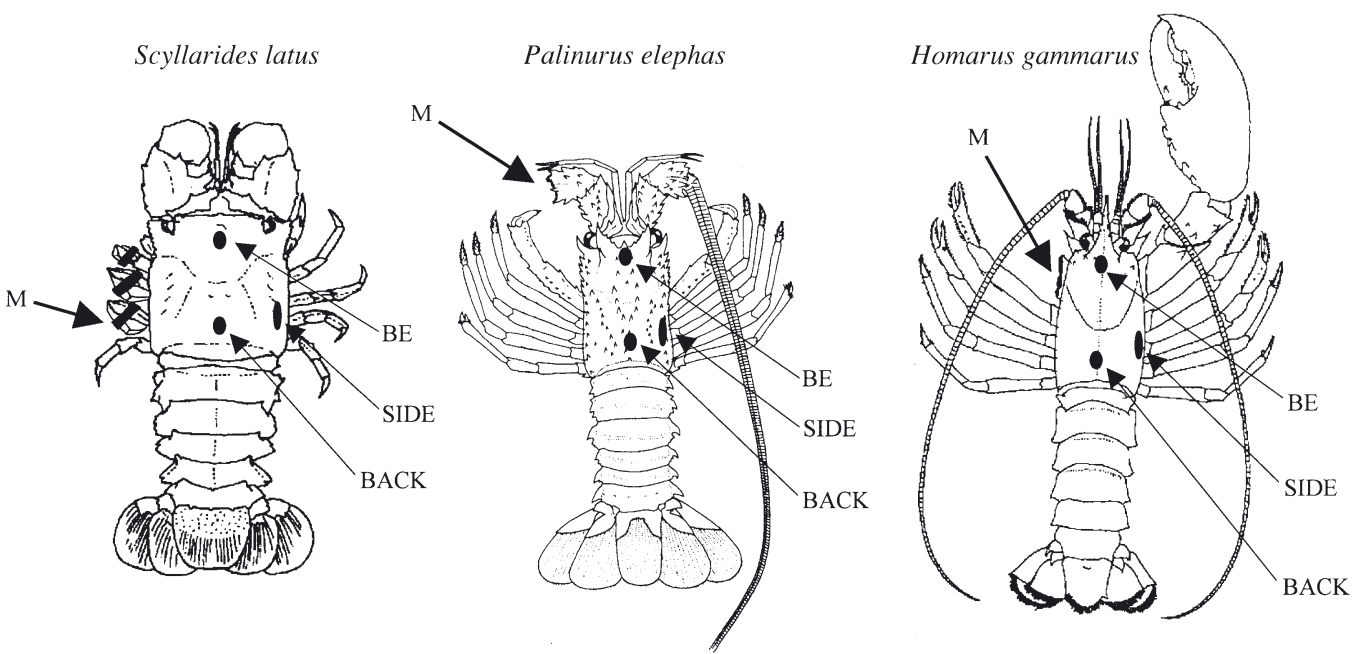

Fig. 2. Scyllarides latus, Palinurus elephas and Homarus gammarus. Line drawings of the 3 lobster species. M: manipulation performed on the respective species (manipulation was on both sides of each lobster, not only on 1 side as shown here). BACK, BE (between eyes, anterior to gastric chamber), SIDE: points on carapace that were punctured using MTS servo-controlled, hydraulic testing machine. (Modified from diagrams of P. Bernucci in: Falciai \& Minervini 1992)

(2) which morphological type of lobster fared better against predation, and (3) the actual strength and thickness of the carapace of each species.

\section{MATERIALS AND METHODS}

Lobsters. Slipper lobsters were purchased from local fisherman in Haifa, Israel. Spiny and clawed lobsters were purchased from suppliers in Colchester, England, and Galway, Ireland, and shipped to us in coolers by airfreight. On arrival, they were gradually acclimated to local water conditions. The lobsters were allowed to completely recuperate from any handling effects for at least 4 wk. They were held communally (separated by species) in tanks with shelters and flow-through, ambient, unfiltered seawater. All the lobsters were fed ad libitum on a variety of local molluscs, including the bivalves Pinctata radiata and Spondylus spinosus, the limpets Patella caerulea and snails Monodonta turbinata. All lobsters used were mature specimens, ranging in size from 73 to $158 \mathrm{~mm}$ carapace length (CL).

Each of the 3 species was used in 2 configurations: (1) intact, and (2) manipulated, whereby a particular (suspected) antipredator mechanism was removed (Fig. 2). Manipulations of spiny and clawed lobsters were made by pinching the autotomy joints with needlenosed pliers and forcing the lobster to drop either its claw or its antennae. Lobsters already lacking 1 of these appendages were purchased from commercial agents, making autotomy of only 1 limb necessary. Slipper lobsters were manipulated by having their walking legs bound with wire ties. Thus manipulated slipper lobsters could not cling to the substrate, manip- ulated spiny lobsters had no second antennae, and manipulated clawed lobsters had no claws. Autotomy of appendages is a natural ability in crustaceans, and forced autotomy did not cause any mortality or sickness during these experiments.

Study site. We drove 30 iron stakes into a relatively featureless, bare area composed of biogenic rock partially covered with seasonal patches of the alga Padina gymnospora. The stakes were arranged into a circle of $12 \mathrm{~m}$ radius, with each stake $2.5 \mathrm{~m}$ apart. Each stake was numbered with a white plastic tag and stood approximately $30 \mathrm{~cm}$ above the substrate. The circle was located $30 \mathrm{~m}$ from artificial tire reefs $1700 \mathrm{~m}$ southwest of Tel Shikmona, Haifa, Israel, at a depth of $18.5 \mathrm{~m}$. This site is known to harbor many fish species including the moray eel, wrasses, sparids, groupers Epinephelus marginatus, E. alexandrinus, and triggerfish Balistes carolinensis, as well as the common octopus Octopus vulgaris (Spanier et al. 1990).

Predation experiments. Previous field experiments (Barshaw \& Spanier 1994a) have shown that predation pressure increases to a maximum over time as the predators in an area alert to an increase in available prey (typical Type II or III numerical response to prey density whereby predation levels off: Holling 1959). As we wished to maintain a constant predation pressure, we baited the field site with fresh and frozen blue crabs and with dead frozen specimens of the 3 lobster species for $3 \mathrm{wk}$ prior to experiments. In this way, we avoided a lower predation rate during the first few runs of the experiment.

We examined 30 lobsters (10 of each species; 5 intact, 5 manipulated) for injuries or missing appendages. We then sexed them, and measured them prior to 
tethering. After tethering, the lobsters were assigned to particular stakes, and taken to the field site. All lobsters were tethered to stakes in the field by two $1 \mathrm{~m}$ long, $50 \mathrm{~kg}$ test monofilament lines knotted and superglued to a black wire tie that was placed around the carapace of the lobsters behind the first 2 pairs of walking legs, as described by Barshaw \& Able (1990) and Barshaw \& Spanier (1994a).

After tethering, the lobsters were observed by SCUBA divers, and their behavior while under attack was recorded on videotape (SONY Handycam Pro Video Hi-8 3CCD-VXIE, RMT 702 camera in an Amphibico 3CCD Pro VX Series) for the first $40 \mathrm{~min}$ after being tethered and again after $4 \mathrm{~h}$. Lobster survival was checked at 4 and $24 \mathrm{~h}$. At $24 \mathrm{~h}$, all surviving lobsters and remains were retrieved. We conducted 4 runs from May to June 1996. Water temperatures ranged from 19 to $22^{\circ} \mathrm{C}$ (mean $=20.6^{\circ} \mathrm{C}$ ) during this period. A lobster was considered preyed upon only if its carapace remains were found in the vicinity of where it had been tethered. In this experiment, probably because of our double-tether system, no lobster escaped and all remains were recovered.

The number of lobsters that survived in the 4 runs of the experiment were initially tested by heterogeneity chi-square analysis (Zar 1996) to ensure that the runs were from the same population, which allowed them to be pooled $\left(4 \mathrm{~h}: \chi^{2}=8.99, \mathrm{p}=0.88 ; 24 \mathrm{~h}: \chi^{2}=22.2\right.$, $\mathrm{p}=0.10)$. The pooled data were then organized in two $3 \times 2 \times 2$ contingency tables for 4 and $24 \mathrm{~h}$ (Table 1 ) These tables were analyzed using chi-square multidimensional contingency tables as demonstrated by Fienberg (1970). The initial part of this analysis was also described by Zar (1996); however, he did not include the interactive method required to analyze for interaction between factors.

The effects of size on the number of lobsters that survived was analyzed using a 3-way ANOVA, where Factor $\mathrm{A}=$ species, Factor $\mathrm{B}=$ manipulation, and Factor $\mathrm{C}=$ survival.

Carapace strength. We conducted 'punch'-tests on the shells of representatives of each of the 3 lobster species to compare the differences in the strength of their carapaces. Lobsters were preserved by freezing and then placed in sealed plastic bags. Prior to testing, the lobsters were thawed and placed in an Inter Technol- ogy MTS (Material Testing System) servo-controlled, hydraulic testing machine at the Materials Laboratory in the Department of Engineering at the Technion Institute for Technology in Haifa, Israel. This machine applies increasing force onto a probe of certain diameter to eventually puncture the carapace of the animal being tested. We chose a probe that approximated the shape, size, and sharpness of the mouth of a triggerfish (the main predator of the lobsters in our experiment). The shell of each individual lobster was tested in 3 areas. Two of these areas represented typical points of attack as noted in the field: Back (immediately posterior to the dorsal cervical groove) and BE (between the eyes and anterior to the gastric chamber of the stomach). The third area tested was a less usual point attack: Side (along the branchial chambers on the side of the carapace just posterior to the cervical and hepatic grooves); Fig. 2 shows these locations for the 3 lobster species. We removed representative pieces of carapace from these same points, measured shell thickness (to $0.01 \mathrm{~mm}$ ) with calipers, and photographed details of the internal carapace structure (Fig. 3). All lobsters were examined for molt condition at this time. Premolt and immediately postmolt individuals were eliminated from the analysis, as their shells undergo changes in calcification at these molt stages.

The results were analyzed with 2 repeated-measure multivariate analyses of variance (MANOVAs) followed by 18 pairwise comparisons using Student's $t$-tests. Repeated comparisons increase the probability of making a Type I error, so we applied the Bonferroni correction at the $\alpha$ level.

Table 1. Scyllarides latus, Palinurus elephas and Homarus gammarus. Null $\left(H_{0}\right)$ and alternate $\left(H_{\mathrm{a}}\right)$ hypothesis for each part of the $3 \times 2 \times 2$ contingency tables, and the $\chi^{2}$ and $\mathrm{p}$-values for each, after $4 \mathrm{~h}$ and $24 \mathrm{~h}$ of predation
Factor
Hypothesis

A: $\quad H_{0}:$ Neither species of lobster nor manipulation has any effect on survival (mutually independent)

$H_{\mathrm{a}}$ : Either species of lobster, or manipulation has an effect on survival

$4 \mathrm{~h}: \quad \chi^{2}=70.2 \quad \mathrm{p}<0.000001 \quad$ Reject $H_{0}$

$24 \mathrm{~h}: \quad \chi^{2}=71.4 \quad \mathrm{p}<0.000001 \quad$ Reject $H_{0}$

B: $\quad H_{0}$ : Species of lobster, irrespective of manipulation, has no effect on survival

$H_{\mathrm{a}}$ : Species of lobster, irrespective of manipulation, has an effect on survival

$4 \mathrm{~h}: \quad \chi^{2}=58.8 \quad \mathrm{p}<0.000001 \quad$ Reject $H_{0}$

$24 \mathrm{~h}: \quad \chi^{2}=69.5 \quad \mathrm{p}<0.000001 \quad$ Reject $H_{0}$

C: $\quad H_{0}$ : Manipulation of lobster, irrespective of species, has no effect on survival $H_{\mathrm{a}}$ : Manipulation of lobster, irrespective of species, has an effect on survival $4 \mathrm{~h}: \quad \chi^{2}=26.8 \quad \mathrm{p}=0.00006 \quad$ Reject $H_{0}$

$24 \mathrm{~h}: \quad \chi^{2}=10.6 \quad \mathrm{p}=0.06 \quad$ Do not reject $H_{0}$

D: $\quad H_{0}$ : There is no interaction between species of lobster and manipulation $H_{\mathrm{a}}$ : There is an interaction between species of lobster and manipulation

$4 \mathrm{~h}: \quad \chi^{2}=8.98 \quad \mathrm{p}=0.01 \quad$ Reject $H_{0}$

$24 \mathrm{~h}: \quad \chi^{2}=3.69 \quad \mathrm{p}=0.16 \quad$ Do not reject $H_{0}$ 

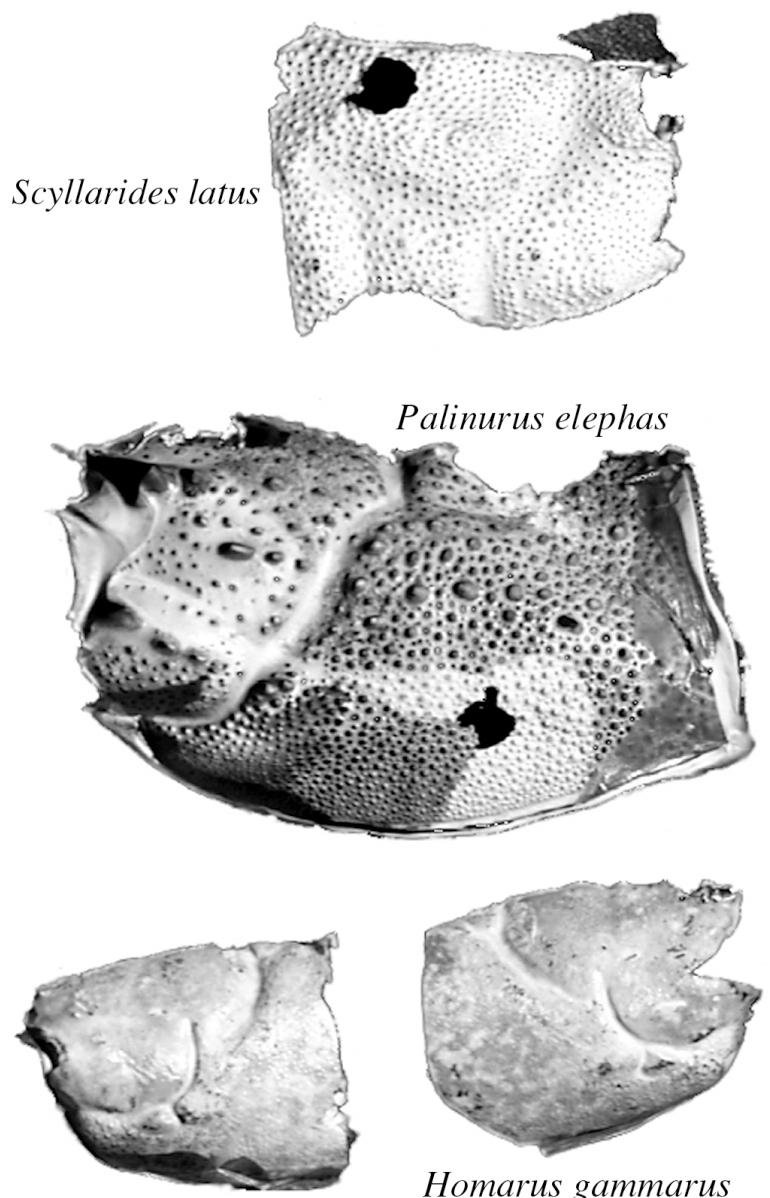

Homarus gammarus

Fig. 3. Scyllarides latus, Palinurus elephas and Homarus gammarus. Photographs of parts of internal carapace of the 3 species showing differences in structure. $H$. gammarus does not have deep pitting of shell, while $S$. latus and $P$. elephas do

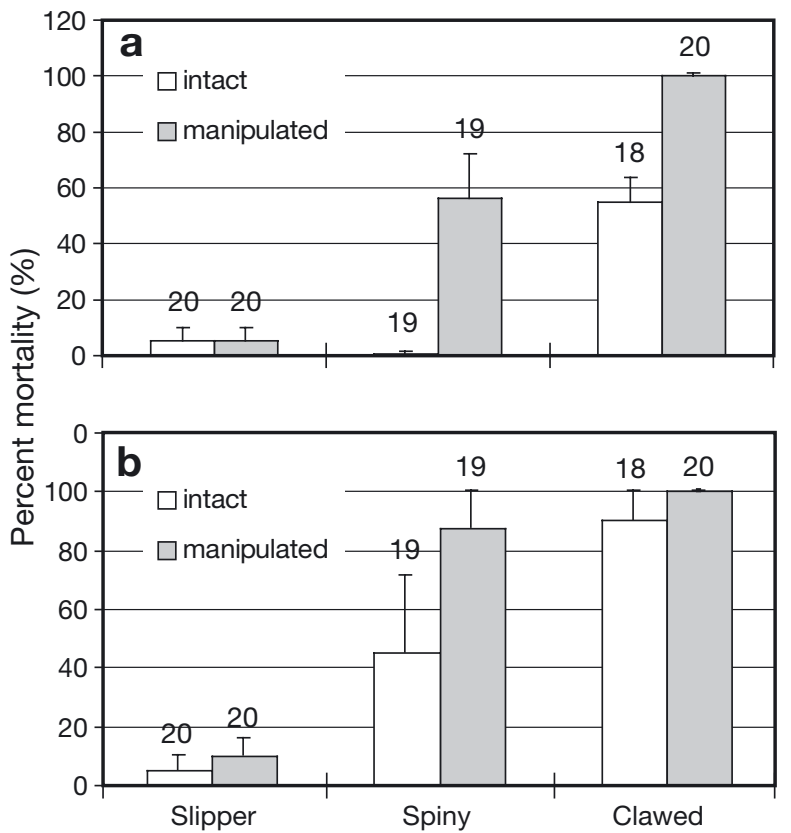

Fig. 4. Scyllarides latus, Palinurus elephas and Homarus gammarus. Percent mortality after (a) $4 \mathrm{~h}$ and (b) $24 \mathrm{~h}$ predation. See Table 2 for pairwise comparisons. Error bars $=\mathrm{SE}_{\mathrm{i}}$ numbers above bars $=$ numbers of lobsters

Intact slipper lobsters and intact spiny lobsters had similar mortality rates, but suffered significantly lower mortality than intact clawed lobsters. Manipulated slipper lobsters, however, suffered significantly lower mortality than manipulated spiny and clawed lobsters, and both manipulated slipper and spiny lobsters displayed significantly lower mortality than manipulated clawed lobsters, with the latter suffering $100 \%$ mortality.
Regression analysis determined the relationships between (1) shell thickness and the force required to puncture it, and (2) size of the lobster and the force required to puncture the shell.

\section{RESULTS}

\section{Predation}

Mortality after 4 h predation (Fig. 4a)

There was no significant difference in mortality between intact and manipulated slipper lobsters. The manipulated spiny and clawed lobsters, however, displayed significantly higher mortality than their intact conspecifics (Fig. 4a, Table 2).
Table 2. Scyllarides latus, Palinurus elephas and Homarus gammarus. $\chi^{2}$ and p-values from pairwise multiple comparisons $(2 \times 2$ contingency tables $)$ of mortality between the 2 treatments and the 3 species after 4 and $24 \mathrm{~h}$ (Fig. 4). Sl: slipper lobster; Sp: spiny lobster; $\mathrm{Cl}$ : clawed lobster, ns: not significant

\begin{tabular}{|c|c|c|c|c|c|}
\hline 4 h mortality & $\chi^{2}$ & $\mathrm{p}$ & 24 h mortality & $\chi^{2}$ & $\mathrm{p}$ \\
\hline \multicolumn{3}{|c|}{ Intact vs manipulated } & \multicolumn{3}{|c|}{ Intact plus manipulated } \\
\hline Slipper & 0.5 & $0.46 \mathrm{~ns}$ & $\mathrm{Cl}$ vs $\mathrm{Sp}$ & 7.1 & 0.008 \\
\hline Spiny & 12.8 & 0.0003 & $\mathrm{Cl}$ vs Sl & 55.9 & $<0.0001$ \\
\hline Clawed & 8.7 & 0.0031 & Sl vs $\mathrm{Sp}$ & 28.4 & $<0.0001$ \\
\hline \multicolumn{6}{|l|}{ Intact } \\
\hline Cl vs Sp & 11.8 & 0.0006 & & & \\
\hline $\mathrm{Cl}$ vs $\mathrm{Sl}$ & 9.4 & 0.0021 & & & \\
\hline Sl vs Sp & 0.0007 & $0.98 \mathrm{~ns}$ & & & \\
\hline \multicolumn{6}{|l|}{ Manipulated } \\
\hline $\mathrm{Cl}$ vs $\mathrm{Sp}$ & 8.2 & 0.0042 & & & \\
\hline $\mathrm{Cl}$ vs Sl & 32.5 & $<0.0001$ & & & \\
\hline Sl vs Sp & 10.4 & 0.0012 & & & \\
\hline
\end{tabular}


Mortality after $24 \mathrm{~h}$ predation (Fig. 4b)

After $24 \mathrm{~h}$, while species continued to have a significant effect on survival (Table 1B), manipulation was no longer important. Therefore, the only pairwise comparisons we could make were of survival differences between species. Slipper lobsters suffered significantly less predation than either spiny lobsters or clawed lobsters, and spiny lobsters suffered significantly less predation than clawed lobsters (Fig. 4b, Table 2).

\section{Size (Fig. 5)}

Among the 3 species $(F=17.8, \mathrm{p}<0.001)$, spiny lobsters were significantly larger than clawed $(F=3.589$, $\mathrm{p}<0.05)$ and slipper $(F=3.846, \mathrm{p}<0.05)$ lobsters. After $24 \mathrm{~h}$, surviving intact spiny lobsters were larger than those spiny lobsters that had been eaten $(F=4.508$, $\mathrm{p}<0.05)$.

\section{Predation observations}

We observed and recorded predation in all 4 runs of this experiment. The predators consisted mainly of groups of 4 to 11 gray triggerfish Balistes carolinensis (a synonym of B. capriscus, pers. comm. of A. Ben-Tuvia, Hebrew University, Jerusalem). Octopuses were twice seen eating clawless Homarus gammarus, but the

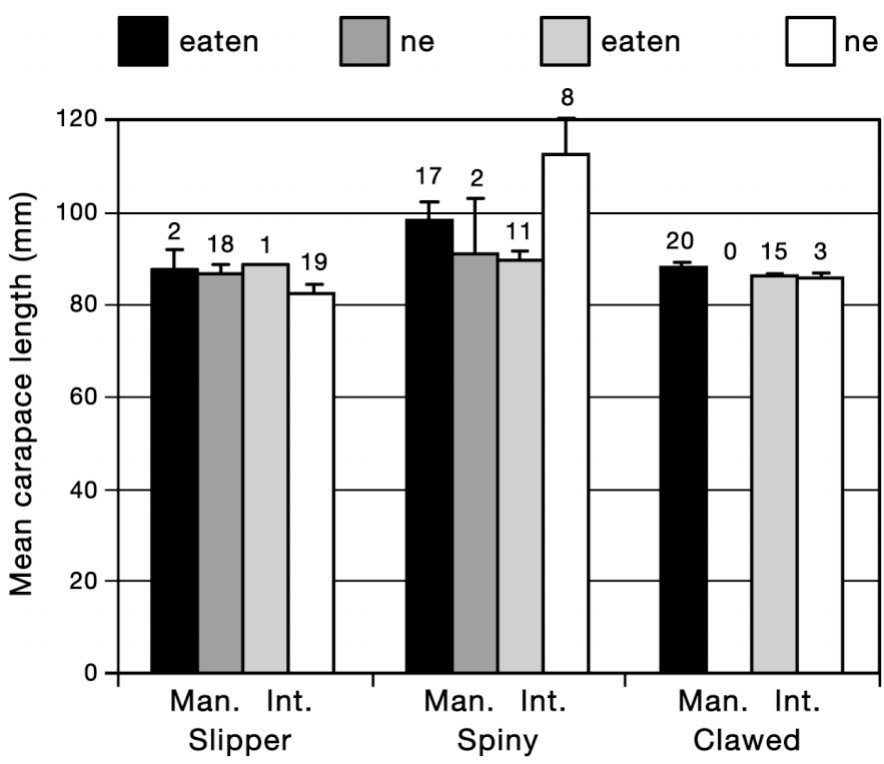

Fig. 5. Scyllarides latus, Palinurus elephas and Homarus gammarus. Mean carapace length (CL) of lobsters eaten and not eaten during field predation experiment. Error bars $=\mathrm{SE}$; numbers above bars = numbers of lobsters; Int.: intact; Man.: manipulated; ne: not eaten lobsters were already dead when these observations took place. We never saw an octopus subdue a lobster.

In a typical attack sequence against slipper lobsters, the triggerfish would approach the lobster several times without actually striking (see Lavalli \& Spanier 2001 for diagramatic sequence of triggerfish attack on slipper lobsters). During these passes, the fish would change from vertical to horizontal swimming, and would seem to 'blow' at the lobster. The slipper lobsters did not move during these passes. The fish would then strike at the lobster; even after such a strike, the slipper lobster would often not move. Finally, the fish would manage to take a bite out of the lobster, often from the flattened second antennae, which would cause the slipper lobster to tail-flip explosively (to the extent of its tether). Once during this experiment, and twice in preliminary experiments, this sudden movement on the part of a slipper lobster startled the attacking fish and stopped further attacks for several minutes. Eventually the fish would subdue the lobster by catching it during a tail-flip, turning it over on its back, biting off 1 or more legs, and finally biting through the ventral sternal plates, as described previously by Barshaw \& Spanier (1994a). The most consistent part of this sequence of behavior was the complete immobility of the slipper lobsters during the first part of the attack.

This behavior of the slipper lobsters differed markedly from the behavior of both spiny and clawed lobsters. Spiny and clawed lobsters would alert to the presence of the fish by turning and facing their attacker. These lobsters always tried to keep their respective weapons (long spiny antennae or claws) facing the fish. Spiny lobsters would fend the fish off with their antennae by pointing or trapping it between the 2 antennae, where they could whip and lunge at the fish to scrape or scratch it (for QuickTime movies of spiny lobster defense behavior against triggerfish see http:// bio.fsu.edu/ herrnlab/cooperativedefense.html). Clawed lobsters mainly used their claws to fend off an attacking fish by jabbing, but they also occasionally snapped at the fish. The strategy of the triggerfish in all these maneuvers was to bite off the eyestalks or disable the weapons of the lobsters. To do this, the fish would either attempt to dart in behind the lobster away from its weapons, or would take bites out of the antennae or the claws until these were rendered less effective as weapons. If the fish did remove a lobster's eyes, then the lobster was no longer able to maintain its position in reference to the fish. At that point, the clawed lobsters were killed with 1 quick bite through their dorsal carapace. Several attacks were required to break through the carapace of spiny lobsters. The most consistent part of this sequence of behavior was the attempt by the lobsters to position themselves with their weapons facing the predator. 


\section{Carapace strength}

Puncture tests (Fig. 6a)

There were significant differences in the force required to puncture the carapaces of the 3 lobster species $(F=67.07, \mathrm{p}<0.0001)$. Significantly more force, up to 3 times as much (paired $t$-test with Bonferroni correction; see Table 3 for all $\mathrm{p}$-values), was required to puncture the carapace of slipper lobsters compared to that of spiny or clawed lobsters at all 3 points on the carapace. At Point Back, significantly more force was required to puncture the carapace of spiny lobsters than to puncture the carapace of clawed lobsters. There was no significant difference between the carapace of spiny and clawed lobsters at either Point BE or Side.

Comparing the 3 different locations on the carapace within groups, there was a significant difference in the force required to puncture the carapace at the 3 different points $(F=52.1, \mathrm{p}<0.0001)$. In slipper lobsters, Points Back and BE were not significantly different, but they were both significantly stronger than Point Side. In spiny lobsters, Point Back was stronger than Point BE, which was stronger than Point Side. Among clawed lobsters, there was no significant difference in the strength of the carapace between the 3 points.

There was a significant interaction between species and location of the puncture test, since the strongest point on the carapace differed as a function of species (between species $\times$ repeated measure, $F=11.4, \mathrm{p}=0.0001$ ).
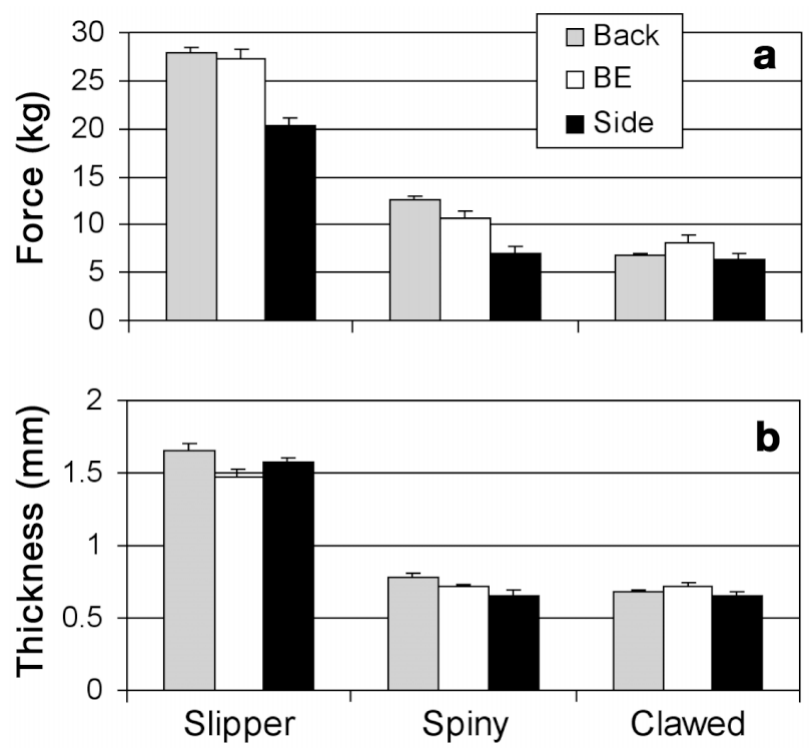

Fig. 6. Scyllarides latus, Palinurus elephas and Homarus gammarus. (a) Mean force required to puncture carapace; (b) mean thickness of carapace. See Table 3 for pairwise comparisons and Fig. 2 for positions of the 3 puncture points. Error bars $=\mathrm{SE}_{i} 14$ slipper, 20 clawed and 18 spiny lobsters were used for measurements
Table 3. Scyllarides latus, Palinurus elephas and Homarus gammarus. $t$ and $\mathrm{p}$ values from pairwise comparisons (Student's $t$-test) of force required to puncture carapace of the 3 species at 3 designated points (Fig. 6a) and of thickness of carapace at the 3 designated points (Fig. 6b). BE: between eyes; Sl: slipper lobster; Sp: spiny lobster; Cl: clawed lobster. Bonferroni correction indicated that only when $\mathrm{p}<0.0028$ were the results significant

\begin{tabular}{|c|c|c|c|c|}
\hline \multirow[t]{2}{*}{ Comparison } & \multicolumn{2}{|c|}{ Force } & \multicolumn{2}{|c|}{ Thickness } \\
\hline & $t$ & $\mathrm{p}$ & $t$ & $\mathrm{p}$ \\
\hline \multicolumn{5}{|l|}{ Slipper lobsters } \\
\hline Back vs Side & 6.0 & $<0.001$ & 2.2 & ns \\
\hline BE vs Back & 0.03 & ns & 4.2 & $<0.001$ \\
\hline BE vs Side & 4.7 & $<0.001$ & 2.5 & ns \\
\hline \multicolumn{5}{|l|}{ Spiny lobsters } \\
\hline Back vs Side & 6.7 & $<0.001$ & 4.2 & $<0.001$ \\
\hline BE vs Back & 5.1 & $<0.001$ & 3.6 & ns \\
\hline BE vs Side & 5.4 & $<0.001$ & 1.9 & ns \\
\hline \multicolumn{5}{|l|}{ Clawed lobsters } \\
\hline Back vs Side & 1.5 & $\mathrm{~ns}$ & 1.4 & ns \\
\hline BE vs Back & 3.2 & $\mathrm{~ns}$ & 2.4 & $\mathrm{~ns}$ \\
\hline BE vs Side & 3.6 & ns & 3.4 & ns \\
\hline \multicolumn{5}{|l|}{ Back } \\
\hline $\mathrm{Sl}$ vs $\mathrm{Cl}$ & 13.8 & $<0.001$ & 21.0 & $<0.001$ \\
\hline $\mathrm{Sl}$ vs Sp & 4.9 & $<0.001$ & 15.1 & $<0.001$ \\
\hline Sp vs Cl & 5.3 & $<0.001$ & 3.3 & $<0.002$ \\
\hline \multicolumn{5}{|l|}{$\mathrm{BE}$} \\
\hline $\mathrm{Sl}$ vs $\mathrm{Cl}$ & 11.4 & $<0.001$ & 16.9 & $<0.001$ \\
\hline Sl vs Sp & 6.4 & $<0.001$ & 12.8 & $<0.001$ \\
\hline Sp vs Cl & 3.0 & $\mathrm{~ns}$ & 0.3 & ns \\
\hline \multicolumn{5}{|l|}{ Side } \\
\hline Sl vs Cl & 12.2 & $<0.001$ & 26.0 & $<0.001$ \\
\hline Sl vs $\mathrm{Sp}$ & 8.1 & $<0.001$ & 18.4 & $<0.001$ \\
\hline Sp vs Cl & 2.8 & ns & 0.03 & ns \\
\hline
\end{tabular}

Carapace thickness (Fig. 6b)

Among the 3 lobster species, there was a significant difference in the thickness of the carapace $(F=262.0$, $\mathrm{p}<0.0001)$. The carapace of slipper lobsters was significantly thicker (up to twice as thick) as that of spiny or clawed lobsters for all 3 points on the carapace. At Point Back, the spiny lobsters' carapace was thicker than that of the clawed lobsters; otherwise there were no significant differences.

Comparing the 3 different locations on the carapace within a species, there was a significant difference in the thickness of the carapace at the different points $(F=19.9$, $\mathrm{p}=0.0001)$. The only significant difference among slipper lobsters was that Point Back was thicker than Point BE. The only significant difference among spiny lobsters was that Point BE was thicker than Point Side. Among clawed lobsters, there was no significant difference in the thickness of the carapace between the 3 points.

There was a significant interaction between species and the location of the puncture test, since the thickest point on the carapace differed as a function of species (between species $\times$ repeated measure: $F=12.8$, $\mathrm{p}=0.0001$ ). 


\section{Regressions}

There was no significant relationship between lobster size and the strength or the thickness of the carapace. However, the lack of relationship is probably due to the small range of sizes tested.

There was a significant positive relationship between carapace thickness and strength for all 3 points in clawed lobsters (Fig. 6b, see Table 4 for all probabilities and $r$ values). Among spiny lobsters, only Point $\mathrm{BE}$ showed a significant positive relationship between carapace thickness and strength (Table 4). There was no significant relationship between carapace thickness and strength for any of the 3 points among the slipper lobsters.

\section{DISCUSSION}

\section{Predation}

The striking outcome of these experiments was that Homarus gammarus, with its massive claws, was the most vulnerable morphological type, while slipper lobsters, which lack any morphological weapon, suffered less predation than either of the other species of lobster. We demonstrated, however, that the claws are important weapons: without them, clawed lobsters are simply bait, and have literally no chance of survival in the open sea. Mortality of Palinura elephas was generally intermediate between that of slipper and clawed lobsters. With their second antennae intact, spiny lobsters suffered little mortality during the first $4 \mathrm{~h}$ of predator pressure, similar to slipper lobsters. Manipulated spiny lobsters suffered greater mortality than intact spiny lobsters, but fared better than manipulated clawed lobsters. In fact, the mortality of manipulated $P$. elephas was similar to that of intact $H$. gammarus. When shelter is at hand, the short-term effectiveness of the weapons of spiny and clawed lobsters could be sufficient to allow them to escape from the predator with the abdominal tail-flip escape-response.

We were unable to demonstrate that clinging to the substrate was an effective antipredatory strategy for

Table 4. Scyllarides latus, Palinurus elephas and Homarus gammarus. $r$ and $\mathrm{p}$-values for regressions on thickness of carapace versus force required to break carapace at 3 different points. Sl: slipper lobster; Sp: spiny lobster; $\mathrm{Cl}$ : clawed lobster; ns: not significant

\begin{tabular}{|lccc|}
\hline Species & Back & BE & Side \\
\hline Sl & $\mathrm{ns}, r=0.44$ & $\mathrm{~ns}, r=0.14$ & $\mathrm{~ns}, r=0.35$ \\
$\mathrm{Sp}$ & $\mathrm{ns}, r=0.24$ & $\mathrm{p}<0.01, r=0.63$ & $\mathrm{~ns}, r=0.23$ \\
$\mathrm{Cl}$ & $\mathrm{p}<0.04, r=0.46$ & $\mathrm{p}<0.03, r=0.48$ & $\mathrm{p}<0.001, r=0.68$ \\
\hline
\end{tabular}

slipper lobsters, as there was no significant difference between intact and manipulated individuals of this species. Earlier experiments have indicated that 'clinging' by these lobsters is a vital part of their strategy against predation (Barshaw \& Spanier 1994a,b). The explanation for this apparent discrepancy is simply that in our experiment not enough slipper lobsters were killed to allow us to test for differences between the 2 treatments. In earlier experiments, slipper lobsters were the only prey offered; consequently, there was considerable predation upon them. In the present experiment, however, the predators preferentially killed the other lobster species: out of the 40 slipper lobsters that were tethered, only 3 were killed (1 intact and 2 manipulated).

Increased exposure to predators decreased the effectiveness of the lobsters' weapons. After $24 \mathrm{~h}$ there was no longer a significant difference between intact and manipulated clawed or spiny lobsters. Both strategies of the fish (to bite off the eyes, and to bite at the claws and antennae) rendered the weapons ineffective. After $24 \mathrm{~h}$, the intact lobsters actually had no functional weapons: they had been 'manipulated' by the predators themselves.

\section{Tethering artifacts}

The tethering technique we used in these experiments has potential artifacts that need to be understood and controlled (Peterson \& Black 1994, Aronson \& Heck 1995). We intentionally attracted predators to our site; thus, we did not measure the natural rate of predation, but instead measured the relative rate of predation on each treatment. What is important is that the act of tethering did not influence any one treatment more than another (Barshaw \& Able 1990). For example, if the tether had made it difficult for clawed lobsters to use their claws, but had had no effect on the armor of slipper lobsters, that would have biased our results. However, we did extensive preliminary tethering tests, observing and videotaping the behavior of the different species while they were tethered in the field, and ascertained that both spiny and clawed lobsters were able to use their weapons without interference from their tethers.

There were indications that flight, particularly explosive unpredictable flight (protean behavior), was a greater part of the antipredatory behavior of slipper lobsters than of the other species. Slipper lobsters are also known to be more efficient swimmers that other lobsters (Spanier et al. 1991). Consequently it could be that the slipper lobsters in our 
experiment were more affected by being tethered than the other 2 species. However, since slipper lobsters suffered almost no predation, this possible artifact cannot have unduly biased our conclusions.

\section{Other experimental artifacts}

While the species we tested are sympatric over most of their ranges (Fig. 1), the coast of Israel, where we did these experiments, is home only to Scyllarides latus. Could it be that slipper lobsters are especially adapted to the particular conditions in this area and for this reason they suffered less predation? The only predator throughout the experiment was the gray triggerfish Balistes carolinensis, which has a global distribution: it is found throughout the Mediterranean, with occasional occurrences in the Black Sea and on both sides of the Atlantic from the North Sea to Angola and from Nova Scotia to Argentina (Lythgoe \& Lythgoe 1992). Consequently, all 3 species of lobster have to contend with triggerfish throughout their range. However, the frequency with which the 3 species of lobster encounter these triggerfish may not be equal. At present there are no publications on the predators or predation rates encountered by adult Homarus gammarus. Perhaps if clawed lobsters had more experience defending themselves from triggerfish they would be less vulnerable. We feel this would be an interesting topic for further study.

\section{Size}

Body size affects the outcome of Predator-prey interactions across many taxa, including these species of lobsters, with greater size often providing a refuge from predators (Eggleston et al. 1992). A small range of sizes were used in the groups of slipper and clawed lobsters, and thus, no effects of size on predation rate were detectable. In the spiny lobster group, however, there was a greater range of sizes, so it is not surprising that the larger intact spiny lobsters had a significantly greater chance of surviving than smaller intact spiny lobsters (Fig. 5). More interesting, perhaps, is that size had no effect on the survival of manipulated spiny lobsters. It appears that larger weapons protect spiny lobsters, not larger body size.

The fact that, in our experiment, spiny lobsters were larger than slipper lobsters but were nevertheless more vulnerable to predation, emphasizes the slipper lobsters' defensive advantage. However, if the clawed lobsters in our experiment had been as large as these spiny lobsters, perhaps the differences in vulnerability between them would have disappeared.

\section{Carapace strength}

The amount of predation suffered by the 3 species of lobsters was best explained by the strength of their respective carapaces, not by the weaponry they possessed. Slipper lobsters suffered the least predation and had the strongest armor, spiny lobsters suffered intermediate predation and had armor intermediate in both strength and thickness, while clawed lobsters suffered the greatest rates of predation and had the weakest armor. However, in the first $4 \mathrm{~h}$ of attack, the weapons of the spiny lobsters combined with their armor resulted in predation at the same low rate as slipper lobsters. It seems clear that increased strength of armor increases the handling time for a predator to a greater extent than the possession of an offensive weapon. Shell strength and resistance to breakage increases as the third power of shell thickness (Wainright et al. 1976, p. 256). Thus, slight increases in thickness should result in substantial increases in the force required to break the shell, minimizing the effect of increased shell strength on the mobility of the lobster. In fact, slipper lobsters (with the strongest shell) swim faster than either spiny or clawed lobsters (Spanier et al. 1991).

The strongest points on the carapace of slipper and spiny lobsters were Points Back and BE, which are the points most exposed during an attack by a fish. It makes sense for these 2 species of lobsters, which use armor as protection against predation, to fortify the most vulnerable spots with the strongest armor. In contrast, there was no difference between the strength of the 3 points on the carapace of the weak-shelled clawed lobsters, suggesting that the Homarus gammarus exoskeleton is not modified as an antipredator mechanism against biting, crushing, or smashing predators. Intraspecifically, only clawed lobsters showed a positive relationship between the thickness of the various points on their carapace and the strength or those points.

\section{Speculations}

These data indicate that, at least for the suite of species we studied, passive, defensive antipredator strategies such as armor are more effective than active, offensive antipredator strategies such as weapons. Is defense generally better than offense? We argue that defensive mechanisms may have general advantages. Weapons probably have a greater cost, as they require energy to grow and maintain, energy for vigilance to monitor the position of the predator, energy to operate and, in the case of arthropods, may be autotomized and require subsequent regeneration. Armor requires 
energy to grow (and of course with arthropods the armor has to be re-grown after each molt) but, once hardened, armor is a nonliving tissue that cannot be sacrificed (as can appendages) and has no maintenance cost. It is interesting that, in contrast to Vermeij (1987) who suggested that 'hardening probably takes longer for heavily armored arthropods', we observed that slipper lobsters hardened within $24 \mathrm{~h}$ of molting, while spiny lobsters took several days, and thin-shell clawed lobsters took many weeks or even months to harden (D. E. Barshaw \& K. L. Lavalli pers. obs.). Our observations are exactly what one would expect if slipper lobsters rely on their armor and the other species do not.

Another advantage of defense is its passivity. If an antipredator mechanism does not require activity, it could work better in concert with avoidance. For example, an organism relying on defence need not keep its weapons between itself and the predator; it can remain motionless even after it detects the predator and may remain undetected longer. Also, morphological weapons themselves could work against avoidance, as they could make an animal easier to detect (Dingle 1983).

Then why develop offensive capabilities? While defensive antipredator characters evolve directly in response to predation, offensive antipredator characters may evolve for multiple purposes, such as capturing food, defense of resources (food, shelter, territory), and obtaining mates (Dingle 1983). Thus, competing pressures may influence their design (Janzen 1981, Vermeij 1982) and they may not be optimized for any 1 particular function. We have shown that the claws of Homarus gammarus do indeed help protect it from predation, so they are an antipredatory mechanism. However, their claws are also used in feeding as well as in intraspecific competition for shelter and for mates (Lavalli \& Factor 1995). The long antennae of spiny lobsters have a sensory function, and a function in intraspecific competition (Zimmer-Faust et al. 1985). Therefore, it is probable that selection for large claws or long antennae is not primarily the result of predation pressure. Defensive antipredator mechanisms, however, develop directly in response to pressure from predators and have no multiple-use constraints on their design. If there are compelling reasons other than antipredator mechanisms for the evolution of weapons, why not have enhanced armor as well? Perhaps this is the mechanism of spiny lobsters that have both weapons and at least some protection from thicker, spinous armor. Of course, there are energy restraints on all organisms and trade-offs in design must be made; thus, it might be impossible energetically to have an organism with the claws of $H$. gammarus and the armor of Scyllarides latus.
The species that we studied are sympatric over much of their geographic distribution (Fig. 1), and are also found at similar depths and in similar habitats (Williams 1988, Holthuis 1991). However, the design of animals is affected not only by their environment (extrinsic factors), but also by ancestral, inherited limitations (intrinsic factors) that determine the directions in which features can evolve (Lauder 1982). The scyllarid and panulirid lobsters are temperate to subtropical in their distribution, and first appeared in the late Triassic. They diverged into many types, with the modern slipper and spiny lobsters appearing in the late Jurassic (George \& Mann 1968). Calcium carbonate does not precipitate as well in colder regions as it does in warmer regions (Vermeij 1987), so perhaps part of the explanation for the heavy armor of the scyllarid line is that it evolved in warmer climates where armor would not be as costly to manufacture.

Based on the many studies showing that competition and predation rates are greater in lower latitudes (Schall \& Pianka 1978, Vermeij 1987) it could be that tropical slipper and spiny lobsters experienced greater predation pressure which resulted in the evolution of specialized adaptations against predators, especially shell-breaking predators. Similarly, shell-breaking predators have been cited as the evolutionary driving force behind the increased shell strength in gastropods living at lower latitudes (Vermeij 1987).

Nephropid lobsters (which include Homarus gammarus) are all temperate to subarctic in distribution, and are relatively old and primitive, having diverged little from their first appearance in the Triassic (Glaessner 1969). We speculate that either (1) clawed lobsters began as and have remained a temperate species, with no impetus to evolve thicker shells, and have thus been able to afford the energetic cost of large claws, or (2) they were competitively excluded from the lower latitudes due to some intrinsic factor such as the maintenance cost of large claws that precluded an evolutionary increase in shell thickness.

Acknowledgements. We would like to thank our assistants Guy Shakhaf and Amir Yurman for all of their help with lobster care and maintenance, diving, photography, and the long hours they put in on these experiments in 1995 and 1996. Stephen Breitstein, our dive operations officer, provided invaluable assistance with tethering, videotaping, and diving. Many others helped us with diving operations during the experiments, and we appreciate their efforts: Yossi TurCaspa, Avinoam Breitstein, Ronit Levy, Oz Goffman, Gregory Lavzin, and Tal Hershkovitz. We thank Donald Rich for originally suggesting a punch test as a way to measure the strength of armor. We also thank him and Dr. Samuel Tarsitano of Southwest Texas State University for reviewing this manuscript and for their many ideas and helpful discussions. We thank an anonymous reviewer who was unusually thorough and helpful, as well as Dr. Michael Childress, particu- 
larly for his statistical suggestions. Efrat Yaskil of the University of Haifa was consulted on the MANOVA tests and provided valuable information. We would also like to express gratitude to Professor Tankum Weller, head of the Materials Laboratory in the Department of Engineering at the Technion, Israel Institute for Technology in Haifa, Israel, for permission to use the MTS servo-controlled, hydraulic testing machine. Ariel Greenwald, his technician, who helped us conduct the punch tests, is also acknowledged. Finally, we would like to thank John Fouere of Cleggan Lobster Fisheries and Christopher Kerrison of Colchester Oyster Fishery for their patience and help in fulfilling our rather odd lobster-purchase requests. During these experiments and the preliminary runs in 1995, K.L.L. was supported by a USIsrael Fulbright Postdoctoral Award. This study was supported by a grant from the Research Authority of Haifa University.

\section{LITERATURE CITED}

Aronson RB, Heck KL (1995) Tethering experiments and hypothesis testing in ecology. Mar Ecol Prog Ser 125: 307-309

Barshaw DE, Able K (1990) Tethering as a technique for assessing predation rates in different habitats: an evaluation using juvenile lobsters, Homarus americanus. US Fish Wildl Bull 88:415-417

Barshaw DE, Spanier E (1994a) Anti-predator behaviors of the Mediterranean slipper lobster, Scyllarides latus. Bull Mar Sci 55(2-3):375-382

Barshaw DE, Spanier E (1994b) The undiscovered lobster: a first look at the social behavior of the Mediterranean slipper lobster, Scyllarides latus. Crustaceana 67:187-197

Brodie ED Jr, Formanowicz DR Jr, Brodie ED III (1991) Predator avoidance and antipredator mechanisms: distinct pathways to survival. Ethol Ecol Evol 3:73-77

Dingle H (1983) Strategies of agonistic behavior in Crustacea. In: Rebach S, Dunham DW (eds) The behavior of higher crustacea. Academic Press, New York, p 85-111

Driver PM, Humphries DA (1988) Protean behaviour: the biology of unpredictability. Clarendon Press, Oxford

Edmunds M (1974) Defense in animals. Longman, New York

Eggleston DB, Lipcius NR, Miller D (1992) Artificial shelters and survival of juvenile Caribbean spiny lobsters Panulirus argus: spatial habitat, and lobster size effects. US Fish Wildl Bull 90:691-702

Endler JA (1986) Defense against predators. In: Feder ME, Lauder GV (eds) Predator-prey relationships. University of Chicago Press, Chicago, p 109-134

Falciai L, Minervini R (1992) Guida dei crostacei decapodi d'Europa. Franco muzzio editore, Padova

Fienberg SE (1970) The analysis of multidimensional contingency tables. Ecology 51:419-433

Fisher W, Bianchi G, Scott WB (1981) FAO species identification sheets for fishery purposes. East Central Atlantic, Vol 5. Department of fisheries and oceans, Ottawa

George RW, Mann AR (1968) The evolution of spiny lobsters (Palinuridae): A study of evolution in the marine environment. Evolution 22:803-820

Glaessner MF (1969) Decapoda. In: Moore RC (ed) Treatise on invertebrate paleontology, Part R, Arthropoda 4, Vol 2. Geological Society of America, Boulder, CO

Harvey PH, Greenwood PJ (1978) Anti-predator defense strategies: some evolutionary problems. In: Krebs JR, Davies NB (eds) Behavioural ecology: an evolutionary approach. Sinauer Associates, Sunderland, MA, p 129-151
Herrnkind WF, Vanderwalker J, Barr L (1975) Population dynamics, ecology and behavior of spiny lobsters, Panulirus argus, of St. John, US Virgin Islands: habitation and pattern of movements and general behavior. Bull Los Ang Cty Mus Nat Hist Sci 20:31-45

Herrnkind WF, Childress MJ, Lavalli KL (2001) Cooperative defence and other benefits among exposed lobsters: inferences from group size and behaviour. Mar Freshw Res 52(8):1113-1124

Holling CS (1959) The components of predation as revealed by a study of small mammal predation of the European pine sawfly. Can Entomol 91:293-320

Holthuis LB (1991) Marine lobsters of the world, an annotated and illustrated catalogue of species of interest to fisheries known to date. FAO Species Catalog, FAO Fisheries Synopsis, no. 125, Vol 13, FAO, Rome

Hunter E (1999) Biology of the European spiny lobster Palinurus elephas (Fabricius, 1787) (Decapoda, Palinuridea). Crustaceana 72:545-565

Janzen DH (1981) Evolutionary physiology of personal defense. In: Townsend CR, Calow P (eds) Physiological ecology: an evolutionary approach to resource use. Blackwell Scientific Publications, Oxford, p 145-164

Juanes F, Hartwick EB (1990) Prey size selection in Dungeness crabs: the effect of claw damage. Ecology 71:744-758

Lauder GV (1982) Historical biology and the problem of design. J Theor Biol 97:57-67

Lavalli KL, Factor JR (1995) The feeding appendages. In: Factor JR (ed) The biology of the lobster Homarus americanus. Academic Press, New York, p 349-393

Lavalli KL, Spanier E (2001) Does gregarious behavior function as an anti-predator mechanism in Mediterranean slipper lobster, Scyllarides latus? Mar Freshw Res 52: 1133-1143

Lythgoe J, Lythgoe G (1992) Fishes of the sea, the North Atlantic and Mediterranean. MIT Press, Cambridge, MA

Maigret J (1978) Contribution a l'etude des langoustes de la cote occidentale d'Afrique. 5. Les larves phyllosomes de Scyllarides et de Palinuridae recueillies au large des cotes du Sahara. Bull l'Inst Fondam Afr Noire Ser A Sci Nat 40: $36-80$

Martins HR (1985) Biological studies of the exploited stock of the Mediterranean locust lobster Scyllarides latus in the Azores. J Crustac Biol 5:650-657

Peterson CH, Black R (1994) An experimentalist's challenge: when artifacts of intervention interact with treatments. Mar Ecol Prog Ser 111:289-297

Phillips BF, Cobb JS, George RW (1980) General biology. In: Cobb, JS, Phillips BF (eds) The biology and management of lobsters, Vol I. Academic Press, New York, p 1-82

Schall JJ, Pianka ER (1978) Geographical trends in numbers of species. Science 201:679-686

Sih A (1985) Evolution, predator avoidance, and unsuccessful predation. Am Nat 125:153-157

Sih A (1987) Predators and prey lifestyles: an evolutionary and ecological overview. In: Kerfoot WC, Sih A (eds) Predation: direct and indirect impacts on aquatic communities. University Press of New England, Hanover, NH, p 203-224

Smith LD (1992) The impact of limb autotomy on mate competition in blue crab Calinectes sapidus Rathbun. Oecologia 89:494-501

Spanier E, Tom M, Pisanty S, Almog-Shtayer G (1990) Artificial reefs in the low productive marine environments of the southeastern Mediterranean. PSZN I: Mar Ecol 11: 61-75

Spanier E, Weihs D, Almog-Shtayer G (1991) Swimming of 
the Mediterranean slipper lobster. J Exp Mar Biol Ecol 145:15-31

Vermeij GJ (1982) Unsuccessful predation and evolution. Am Nat 120:701-720

Vermeij GJ (1985) Adaptations, effects, and fortuitous survival: comment on a paper by A. Sih. Am Nat 125:470-472

Vermeij GJ (1987) Evolution and escalation: an ecological history of life. Princeton University Press, Princeton, NJ

Editorial responsibility: Kenneth Heck (Contributing Editor), Dauphin Island, Alabama, USA
Williams AB (1988) Lobsters of the world-an illustrated guide. Osprey Books, Huntington, NY

Zar JH (1996) Biostatistical analysis, 3rd edn. Prentice Hall, Upper Saddle River, NJ

Zimmer-Faust RK, Tyre JE, Case JF (1985) Chemical attraction causing aggregation in the spiny lobster, Panulirus interruptus, and its probable ecological significance. Biol Bull 169:106-118

Submitted: April 18, 2002; Accepted: March 10, 2003

Proofs received from author(s): June 23, 2003 